\title{
The Secret behind Strategic Information Management over the Success of Agro-Processing and Retail Industries-Case Study Wal-Mart
}

\section{Mussa $\mathrm{HI}^{*}$ and Zhi Zhang W}

College of Economics and Management, Southwest University, China

\begin{abstract}
Until recently, business sector has been an important organ to contribute toward sustainable development in the society, which is why, many organizations have been launched in different parts of the World to achieve toward these prosperity. It is suggested however, in order to have an outstanding business entity; therefore, it is keen to have an outlined strategic plan both in management and information system. This piece of literature, thereby, intends to establish the principles which underpinning the role of strategic planning in terms of overall management of the entity and indeed the role of information systems in the organization and its contribution to achieve the firm's specific and general objectives.
\end{abstract}

Keywords: Information system planning; Organization mission; Swot analysis; Agro-processing and manufacturing; Critical success factor

\section{Introduction}

Basically, business has been major drive of development in terms of national and international pattern. This has been contributed however, by providing crucial effects such as employment, technological advancement, improving infrastructure, boosting cultural heritage, increase relationship among the people and nations as well as providing financial strength. Because of this positive effects therefore, many organizations have been launched in different parts of the world based on manufacturing such as automobile manufacturing industries like Toyota, Vauxhall, and Benz. There are also servicing industries such as airline industries, telecommunication industries as well as banking industries. Most of these organizations however, aimed and determines to provide good services in order that they can satisfy not only their customers but the shareholders by achieving the business goals and objectives [1]. It is learnt, however, in order to achieve the intended objectives; the organizations must put in place an outlined strategic information management so that they can fulfil its goals. This subtopic will thereby provide a substantial picture for the management need to swiftly have strategic planning within the organization [2-5]. The word "strategy" can therefore be defined as "a clear vision of what the organization will be; based on sustainable competitive advantage; specifying what should be done and the resources required" by Howard Thomas. Nevertheless, it can also be defined as "Something that organization needs or uses in order to win, or establish its legitimacy in the world of completive rivalry... strategy is what makes a firm unique, a winner or a survivor" by Howard Thomas. More remarkably, strategy is a very important element in any organization this is because it helps to provide a fantastic understanding of the firm's competitive advantage and outlining a specific objectives but also to improve the company product and services, selecting a good place for business, to search for market and the customers, improving resources required and give the chance to implement the plan. This piece of work thereby, will examine how Wal-Mart the North American born retail giant consider the role of strategic information management in the run of this organization [5-7]. The work will be accomplished sincerely with several sources of such as company's annual report, newspapers, the company's magazines, case study and textbooks.

\section{Background and Assumptions}

The Wal-Mart family has emerged as the most successful North
American retail giant in the world. The firm has been established since 1960s, from the United States of America. The company is basically dealing with the retail business which involves different types of products and services such as grocery, fresh food and frozen and clothes $[7,8]$. The company operates in more than 100 countries and employ thousands of people around the world. The firm is estimated to have more than 7800 stores around the world. It is also thought to serve more than 100 million customers each year and indeed employ more than 2 million associates globally. In the United Kingdom the firm has been named as Asda and has been as popular for its song as the cheapest supermarket in the United Kingdom [8-10]. According to Fishman the Americans spend \$26 million each hour thereby WallMart emerges as the very strong organization in the world in term of finance. The key success of this firm in nothing but is deliberate efforts made in terms of efficiency and effectiveness [11-15]. This is to say that Wal-Mart has made tremendous effort toward efficiency in every department and thereby has been described as the major sources of achievement. However, the catalyst toward this achievement has been associated with the successful installation of the strategic information system. Thereby, the technological devices, services and innovations such as POS, the store performance tracking, satellite system, the UPC as well as the crucial marketing research all have indeed made a huge and significant contribution.

\section{Agro-processing and Manufacturing}

Indeed, food processing and manufacturing such as that of beverage, tobacco, fibre, yarn and thread mills as well as the tanneries are making huge impact in the agribusiness industries. The food processing and manufacturing industry may well change the raw agricultural commodities in either ingredient for further processing or indeed as the final consumer products such as soybeans, bakers, meat packers, flour millers, wet corn mills, breakfast cereal companies,

*Corresponding author: Mussa $\mathrm{HI}$, College of Economics and Management, Southwest University, China, Tel: +8618375723831; E-mail: ibramussa@yahoo.com

Received May 20, 2016; Accepted July 29, 2016; Published August 02, 2016

Citation: Mussa HI, Zhi Zhang W (2016) The Secret behind Strategic Information Management over the Success of Agro-Processing and Retail Industries-Case Study Wal-Mart. J Glob Econ 4: 204. doi: 10.4172/2375-4389.1000204

Copyright: $\odot 2016$ Mussa HI, et al. This is an open-access article distributed under the terms of the Creative Commons Attribution License, which permits unrestricted use, distribution, and reproduction in any medium, provided the original author and source are credited. 
brewers, snack firms, fruits and juice, diaries firm, vegetables, as well as the tanneries are the great examples of food and fibre processor and manufacturers [16]. In 2007, United States shipment in this sector account for $\$ 590$ billion (2007 Economic Census). However, due to growing need for vertical and horizontal integration many firms now engage in processing in the products such as animal feed, grain milling and meat packaging [17]. More significantly, the situation where commodities required to be shifted from one point to another that is where the transportation and logistics firms come into action. These firms facilitate the transportation of products from farmers to processors or manufacturers and they play crucial roles toward agribusiness and that is where linkages between the industries occur.

\section{Mission Statements}

Basically, for any organization to succeed it need to have an outlined planning to enable it operate in any of its departments. The Total Quality Management (TQM) is an important tool that needs to be considered when focusing on the strategic planning [18-20]. As that is where the organization establishes its Mission Statement which help to implement its activities and achieve it intended objectives. The Mission Statement can therefore be defined as "unique purpose that set a company apart from other companies of its types and identifies the scope of its operations". It is studied, however, that when associating mission statement with any organization the mission must be able to answer the important five questions such as "What is our business? Who are our customers? What is the value of our customers? What will be our business? What should our business be?" Drunker. The firm in question, its mission statement based on saving money for the customers in order to live better in the society. Wal-Mart believes therefore, that when people work together as a team they will reduce the cost of living and ultimately both will live together in the better life. In this respect, therefore, in order to save money every day for their customers and fulfil its mission, Wal-Mart decided to outline peculiarity in not only the policies and principles but also rules, process as well as procedures thereby to create unique culture within the organization [21]. The sublime about this uniqueness is basically, it involves magnificent steps such as "open door policy" whereby the managers are free to their employees at different levels, the "sundown rule" which deliberately tends to answer the queries from the customers, employees as well as the suppliers at the same day, the "Grass Root Process", the Basic Beliefs and Values such as Respect for the individual, Services for our customers and Striving for Excellence all have created to stress on the mission [22]. It is also focuses on 10 foot-rule to help customers, the servant leadership, and Wal-Mart Cheer. After all, these principles have largely help the organization to achieve its goals therefore become one of the most successfully retail giant in the world [23-25]. The role of information system cannot be forgotten here, this is because in order to implement these principles and policies there must be proper devices to be able to achieve the objectives. Therefore, important equipment such as computer system connected with the intranet, extranet as well as the internet usage has been installed. This information system connects the whole system together and monitors the whole transaction process alongside the customer services and particularly online purchasing. Through this technology, therefore, Wal-Mart has overtaken many retails company and thus become the most successful retail in the globe. This was because of the widen market that the firm has made globally [26]. However, many organizations have now realized the significant of this technology and start to apply and provide competitiveness to Wal-Mart.

\section{Environmental Analysis}

Genuinely, the company is part of the society, this in because it is situated within the public and it is intended to serve the public at large and definitely it is owned by the people from the public. In this perspective, therefore, the company must be affected by the society behaviour in terms of social, political, economic, technological and legal affairs [27]. In terms of economic perspectives, the company may be affected by several factors based on the economic cycle, for instance during the economic downturn the organization may be affected in one way or another. Despite the fact that, over this issue, the company has no control but it may create policies to reduce the harms. Wal-Mart has been so careful when dealing with this matter by trying to take efforts such as restructuring the management and introduce new roles [2830]. This was done to reduce cost and maximize profit. On the side of politics, it appears that the policy maker may introduce any policy in the interest of the countries. For instance the issue of immigration cap adopted by the Government in the UK may affect the company in term of labour force and ultimately damage the business [31]. However, to deal with this matter, Wal-Mart tends to offer very flexible contacts with a lot of incentives to the employees to make their job safe and secure. On the other hand, several laws are now enacted that may in one way or another affect the business; this may be directed toward tax and tariffs. This issue can be tackled by increasing the price of the products in which the Wal-Mart deals with. Moreover, with regard to socio matters, the organization may be affected in terms behaviour, culture, health consciousness as well as the development of the society. The organization responded however by increasing production to feed large number of peoples, to support cultural activities, and particularly by introducing health centre such as pharmacy to deal with the customer health in which the company has been so concerned. In addition to that, any organization can be affected by technological factor such as internet use. Under such circumstances, the organization now has to change its policy to go side by side with the technological change. The beauty on this matter is basically, to help the organization to expand its market globally. In response though, Wal-Mart has been a good player of technological advancement by putting the devices in place such as in store product checking, and the use of satellite and internet which is why it has expanded its market worldwide and indeed increase efficiency in the business operation (Figure 1).

\section{Porter's Five Forces of Industrial Effectiveness}

Essentially, despite its size, any organization in order for it to develop it requires an outlined strategic information management being put in place [32]. However, Porter has increasingly, suggest that "decision in the business can be classified as strategic if they involve some innovations and difference that result in sustainable advantage". In other words, the strategic planning may refers to those plans which are intended to distinguish from one organization to the others to attain sustainable future. This may be achieved through partnership of operational effectiveness as well as the strategic planning. More profoundly, any organization should not play down the threats surrounding its rivalry. Under such circumstance therefore, the strategic management will underpin the steps to be employed in order to gain competitive advantage [33]. To discuss this matter however,

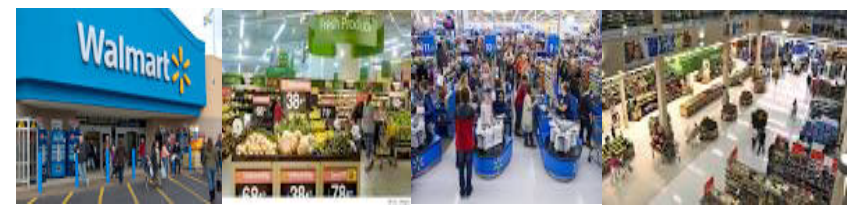

Figure 1: Strategic information management of agro-processing in Wall-Mart. 
it is important to understand what exactly are the sources of the competition in several situations and the measures to be taken to sort out these issues as far as the Wal-Mart concerned. Basically, the rivalry are intensified by things such as huge number of industries, the slow growth of the market. The very high fixed cost, the huge logistics and storage costs, the availability of the substitute goods or services as well as the huge exit barrier when the firm tend to change the type of products or services to deliver, the industry shakeout and complexity and utterly the industrial instability due to culture or policies or philosophy. On the other hand, the measures that may be taken by the firm to gain competitive advantage include price minimizing or maximizing, the improvement of the product or services differentiation such as in terms of developing product features and encourage innovations, efficiently and creatively using the logistics and distribution channels as well as the establishment of the proper guidelines with the suppliers on how to distribute the products or services [34]. Wal-Mart however, has been so concern about these matters and responded by reducing the price of its products and indeed advertising it as the cheapest supermarket in the UK and particularly efficiently using its distribution channels and logistics to gain competitive advantage hence become the most successful retail in the world. On top of that, the product substitute has been the major sources of organization shaking. That is to say that, according to Porter availability of the substitute products may weaken the sale of the other products or services, but to avoid this contradiction Wal-Mart tend to change the price to attract the customers to stick with the particular product. According to Porter however, the buyer power also tends to give impact on the organization, that is to say there is huge relationship of industry if the buyer power is strong or weak. Basically, buyer may be powerful if whether the potential buyer is indeed concentrated in connection with the market share, or if whether the buyer has significant proportion of the potential output and incredibly the possession of the buyers integration threat. In response however, Wal-Mart, is significantly aware about the matter and several measures employed to reduce the risk. Moreover, Michael Porter suggest that, in order for the organization to produce it need to have important element such as raw material, labour, market and other important component. This situation will establish a business relationship with the organization. Thereby the supplier power is likewise need to be considered and thus can influence the production. In addition to that, the barrier to entry refers to the situation to which the organization may enter or exit the barrier [35]. These may be contributed by the government barriers, or hiding the knowledge access from other firms, or lack of facilities. The organization may exit the market if the cost is low. However, Wal-Mart has made an incredible effort in terms of efficiency to get rid with any threats caused by the five forces.

\section{SWOT Analysis}

Basically, in order to provide an outstanding strategic planning the management should be aware to analyse the crucial theory which is said to be SWOT analysis. The latter "S" stand for strength, where under this circumstance it reveal how the company is generally strong in the manner it operate. In connection with the Wal-Mart however it shows that the firm is extremely powerful retail giant in the world, this is basically due to several issues such as reputation for finance, the organization value as well as the efficiency and commitment and indeed wide range of the products. However, in terms of weakness the firm has in the brisk pace to expand its market by either mergers or licensing and particularly franchising. This situation may affect the organization in one way or the other as the operation can lose control [36]. On top of that, Wal-Mart has a huge opportunities by being able to operate in several country around the world thereby widen its markets increasingly in Europe and China to acquire huge market share an indeed attain the competitive advantage. After all, the WalMart is under severe threat from rivalry, this is because the firm is on the top position in the globe therefore in order to retain its position from being damaged it need to have quality management to provide clear policies that may lead to effectiveness and efficiency to enable the organization to achieve it intended objectives.

\section{Competitive Advantages}

More significantly, the organization must have several set ups in terms of policies, skills, innovations as well as the principles to attain competitive advantages against the rival. The competitive advantage can thereby be defined as "the strategic advantage one business entity has over its rival entities within the competitive industry". According to Porter however, there are four strategies that may assist the organization to attain competitive advantage. These include differentiation focus, cost focus, cost leadership as well as differentiation. However, the major secret of the Wal-Mart competitive advantage base on the price management $[11,37]$. This is to say, the cheap price philosophy from its own brand name ensures and attract the customers to buy the product and thus expand the market and organization growth. On the other hand management strategy helps to provide flexible management strategy and encourage managers and colleagues to have job security and also feel that they belong to the firm. However, the Wal-Mart has gain competitive advantages by effectively and efficiently organizing its operations based on the logistics and distribution channel and certainly supply chain management monitoring. Wal-Mart (Asda) was among the first organization to introduce online purchase, through this strategy it overtake retail such as Tesco and Sainsbury in terms of the market share. Likewise, it was the most. Moreover Wal-Mart is one among the frontline retail of supervising, implementing cultural diversity in the organization. Indeed, the use of Radio frequency Identification Technology and Universal Bar Code help the organization efficiency by transmitting information with the suppliers and recognizes the transactions system.

\section{Critical Success Factors}

More significantly, every organization must provide a set of guidelines to outline the most important elements that may help the organization to operate and settle. Basically, it includes the genuine factors such as characteristics, conditions or activities that has direct impact toward the efficiency, or effectiveness, as well as the viability of the firm, the project and indeed the entire programme. In this respect therefore, the activities that connected to the CSR should be performed, organized and particularly operated in the very highest level to help the organization to achieve its intended objectives. In terms of Wal-Mart however, the major secret of its success is the advantage it took regarding information technology, it guarantee cheap price by merchandizing by its own brand, and the universal bar code help to increase efficiency, joint ventures such as in China have put Wal-Mart where it is at the moment. On the other hand, one can not dispute the role played by JIT strategy employed by Wal-Mart. These operational logistics strategies pave the way toward the firm success by ensuring that the goods and services are available on time by the stockholders and shareholders. These entire factors helps the organization to advance and gain a huge market share in the world and thus become the most successful retail giant in the World. The current success factors however, may be employed to help the organization to overcome the existing weakness and threats and indeed retains its market share and position. 
Citation: Mussa HI, Zhi Zhang W (2016) The Secret behind Strategic Information Management over the Success of Agro-Processing and Retail Industries-Case Study Wal-Mart. J Glob Econ 4: 204. doi: 10.4172/2375-4389.1000204

\section{Strategy Discussion and Conclusion}

Indeed, in discussing on the company strategic plans one must believe that decent organization would demand a clear strategic plan to help the organization to achieve its intended objectives. Verily, strategy plays significant role within the organization, however, in order to have that in place and indeed sound efficiently and effectively one should involve criteria which includes not only clear vision, objective settings, and crafting strategy but the implementation, assessment and evaluate the strategy. In other words, one should bear in mind strategic elements in terms of the mission statement, the swot analysis, the environmental analysis and particularly proper guidelines on strategic decision making as well as its implementation to assist objectives achievability. Perhaps even more importantly, the strategy may well help the firm to attain its goals in different ways such as that of understanding the weaknesses and strengths of the firm, as well as the awareness in terms of the environment upon which the firm is surrounded. Moreover, it will also be aware on the opportunity that the organization should take to gain competitive advantage, and finally, helps to recognize the threats which face the firm and therefore prepare the measures to sort out the problems. In respect of this outlook however, the Wal-Mart seems not to turn blind eyes in terms of strategy. Its extraordinary efforts, in the strategic planning help the firm to secure stunning victory in the retail quality. The effectiveness and efficiency has been the key success of the firm. This has huge contribution to increase cultural diversity; the total quality management and particularly the role of technology and innovation have intensified this success. In addition to that, it has made an incredible impact through JIT strategy as it is always makes sure that the services and products are available on time. Moreover, strategy to involve local communities in making decision in terms of business has been tremendous ahead of the company success. However, the firm could have done better by grabbing market share by increasing the number of stores in Africa where it seems to have none or little interest despite taking part in supplying activities. In fact, all these matter have been contributed by the intelligent revolution in terms of information systems upon which the firm has been conform to. The application of computer networks based on data transfers in the form of internet, extranet and intranet has been tremendously engaged. On the other hand, the firm should also consider any other form of business to stress its strength, grabbing the market share and retain the position against its rivalry.

\section{References}

1. Porters ME (2004) Competitive Strategy, techniques for analysing industry and competitors. New York.

2. Robert D (2006) Strategic Information Management. Elsevier Butterwoth Hainemann, London.

3. Earl MJ (1989) Management Strategies for Information Technology. Pearson Prentice Hall, London.

4. Bronzite M (2012) System Development (Strategic Frame Work). Springer Ltd, London.

5. Clarke S (2001) Information Systems Strategic Management. London.

6. Mclead R, Schell G (2007) Management Information System. London.

7. Robson W (1997) Strategic Management Information System. London.

8. Bocij P (2003) Business Information Systems-Technology Development for e-business. London.

9. Talbot M (2003) Make Your Mission Statement Work. How to Book Ltd

10. Greasley A (2007) Operations Management. SAGE.

11. Alter S (1994) Business Information System. Prentice Hall international (Ltd), London.
12. Bingham J, Daures G (1994) System Analysis. MacMillan Press Ltd, London.

13. Guy F, Avison D (2003) Information Systems Development (Methodologies, Techniques \& Tools. MacGraw-Hill Education, United Kingdom.

14. Hale R, Whitlam P (1998) Target Setting and Goal Achievement. Kogan Page Ltd, United Kingdom.

15. Bowdin G (2006) Event Management. Elsevier, London.

16. Johnson J, Scholes K (2002) Exploring Corporate Strategies (Case \& Text) Prentice Hall, London.

17. Jonhson G (2008) Exploring Corporate Strategy. Prentice Hall, London.

18. Kay J (2005) Foundation of Corporate Strategy (The Most Important Contribution To Business Thinking In Decade). Oxford University Press, London.

19. Lynch R (2006) Corporate Strategy. Prentice Hall \& Pearson Education, London.

20. Sookun M (2011) Environmental Analysis. London School of Commerce, London.

21. Mintberg H (2009) Strategy Safari. Prentice Hall, London.

22. Niale B, Pike R (2005) Corporate Finance \& Investment (Decisions \& Strategies). Prentice Hall, London.

23. Pottabathni G (2009) Wall-Mart Strategy, Case Study.

24. Bronzite M (2000) System Development (Strategic Frame Work). Springer Ltd, London.

25. Meek (2002) Strategic Marketing Management (Planning \& Control). Elsevier Science Limited, Italy.

26. Mursay I (2006) The Franchizing Handbook. Kogan Page Limited, London.

27. Wall-Mart (2009) Retail Colleague Handbook. London.

28. Robson W (1997) Strategic Management Information System. Prentice Hall, London.

29. Robert DG (2006) Strategic Information Management. Elsevier Butterwoth Hainemann, London.

30. Lynch R (2012) Strategic Management. Peason education, London.

31. Balogun J, Hailey H (1999) Exploring Strategic Change. Prentice Hall, London.

32. Kotler P (1999) Kotler in Marketing (How to create, Win and Dominant Market) Free Press United States.

33. Stickland AJ, Gamble J, Peteraf M, Thompson A (2012) Crafting and Executing Strategy (Concepts and Cases). McGraw-Hill, New York.

34. Kotler P, Keller KL (2009) Marketing Management. Peason Education, London.

35. Lynch R (2003) Corporate Strategy. Essex: Prentice Hall, United Kingdom.

36. Robert A, Clayton M, Steven W (2004) Strategic Management of Technology and Innovation. McGrow Hill, New York.

37. Johnson, Scholes (2012) Exploring Corporate Strategy. Peason Education, London. 